\title{
Article \\ Human Antibody Domains and Fragments Targeting Neutrophil Elastase as Candidate Therapeutics for Cancer and Inflammation-Related Diseases
}

\author{
Xiaojie Chu ${ }^{1, *(1)}$, Zehua Sun ${ }^{1}$, Du-San Baek ${ }^{1}$, Wei Li ${ }^{1}$, John W. Mellors ${ }^{1,2}$, Steven D. Shapiro ${ }^{3,4}$ \\ and Dimiter S. Dimitrov $1,2, *$ \\ 1 Center for Antibody Therapeutics, Division of Infectious Diseases, Department of Medicine, \\ University of Pittsburgh School of Medicine, Pittsburgh, PA 15261, USA; ZES20@pitt.edu (Z.S.); \\ DUB5@pitt.edu (D.-S.B.); LIWEI171@pitt.edu (W.L.); jwm1@pitt.edu (J.W.M.) \\ 2 Abound Bio, Pittsburgh, PA 15219, USA \\ 3 Department of Medicine, University of Pittsburgh School of Medicine, Pittsburgh, PA 15261, USA; \\ shapirosd@upmc.edu \\ 4 University of Pittsburgh Medical Center (UPMC), Pittsburgh, PA 15261, USA \\ * Correspondence: xiaojie1003@pitt.edu (X.C.); mit666666@pitt.edu (D.S.D.); Tel.: +1-412-648-4232 (X.C.); \\ +1-412-383-4702 (D.S.D.)
}

Citation: Chu, X.; Sun, Z.; Baek, D.-S.; Li, W.; Mellors, J.W.; Shapiro, S.D.; Dimitrov, D.S. Human Antibody Domains and Fragments Targeting Neutrophil Elastase as Candidate Therapeutics for Cancer and Inflammation-Related Diseases. Int. J Mol. Sci. 2021, 22, 11136. https:// doi.org/10.3390/ijms222011136

\section{Academic Editors:}

Ivo Meinhold-Heerlein and Ahmad Fawzi Hussai

Received: 29 September 2021

Accepted: 12 October 2021

Published: 15 October 2021

Publisher's Note: MDPI stays neutral with regard to jurisdictional claims in published maps and institutional affiliations.

Copyright: (c) 2021 by the authors. Licensee MDPI, Basel, Switzerland. This article is an open access article distributed under the terms and conditions of the Creative Commons Attribution (CC BY) license (https:// creativecommons.org/licenses/by/ $4.0 /)$.

\begin{abstract}
Neutrophil elastase (NE) is a serine protease released during neutrophil maturation. High levels of NE are related to lung tissue damage and poor prognosis in cancer; thus, NE is a potential target for therapeutic immunotherapy for multiple lung diseases and cancers. Here, we isolate and characterize two high-affinity, specific, and noncompetitive anti-NE antibodies Fab $1 \mathrm{C} 10$ and $\mathrm{V}_{\mathrm{H}}$ 1D1.43 from two large phage-displayed human Fab and $\mathrm{V}_{\mathrm{H}}$ libraries. After fusion with human $\operatorname{IgG1}$ Fc, both of them $\left(\mathrm{V}_{\mathrm{H}}-\mathrm{Fc}_{\mathrm{C}} 1 \mathrm{D} 1.43\right.$ and IgG1 1C10) inhibit NE enzymatic activity with $\mathrm{V}_{\mathrm{H}}-\mathrm{Fc}_{\mathrm{C}} 1 \mathrm{D} 1.43$ showing comparable inhibitory effects to that of the small molecule NE inhibitor SPCK and IgG1 1 C10 exhibiting even higher (2.6-fold) activity than SPCK. Their epitopes, as mapped by peptide arrays combined with structural modeling, indicate different mechanisms for blocking NE activity. Both $\mathrm{V}_{\mathrm{H}}-\mathrm{Fc}$ and IgG1 antibodies block NE uptake by cancer cells and fibroblast differentiation. $\mathrm{V}_{\mathrm{H}}-\mathrm{Fc} 1 \mathrm{D} 1.43$ and IgG1 $1 \mathrm{C} 10$ are promising for the antibody-based immunotherapy of cancer and inflammatory diseases.
\end{abstract}

Keywords: therapeutic antibodies; neutrophil elastase; inflammatory disease; cancer

\section{Introduction}

Neutrophil elastase (NE) is a serine protease released by neutrophil degranulation or during the formation of a neutrophil extracellular trap (NET) [1,2]; it is generally considered the main contributor of neutrophil protease activity. Neutrophils are the most abundant white blood cells and play a major role in host defense against bacterial infection [3]. They can rapidly release cytokines, chemokines, reactive oxygen species, and proteases to help defend against bacterial infection and regulate inflammation [4]. However, the prolonged activation of neutrophils contributes to the pathophysiological changes in lung and causes acute or chronic inflammatory diseases such as chronic obstructive pulmonary disease (COPD) [5], cystic fibrosis [6], acute lung injury [7], and acute respiratory distress syndrome bronchiectasis [8]. NE, as an important regulator of the inflammatory response [9], can degrade all of the extracellular matrix proteins such as elastin, collagens, fibronectin, and lung surfactant protein and can also activate lung epithelial cells to produce inflammatory cytokines which could further activate neutrophils, then cause acute lung injury or fibrosis $[10,11]$. The level of NE activity and the cell count of neutrophils were highly elevated in sputum plasma from cystic fibrosis patients compared with healthy individuals [12,13]. Similarly, COPD patients also have a two-fold higher level of NE activity than healthy 
individuals in serum and bronchoalveolar lavage (BAL) fluid [14]. Despite respiratory diseases, many studies have shown that NE could also promote tumor proliferation through degrading IRS-1 and activating the PI3K-AKT signal pathway $[15,16]$. High NE activity is an indicator of poor prognosis in breast cancer, colorectal cancer, and non-small cell lung cancer [17-20]. In addition, NE activity could promote the adhesion of pancreatic cancer cells to vascular endothelial cells through stimulating the E-selectin expression [21]. Thus, the inhibition of neutrophil elastase activity can be considered a novel druggable strategy in cancer and inflammatory diseases.

Several NE inhibitors have been evaluated in mouse cancer models, including sivelestat and curcumin. Even though NE inhibitors inhibit NE activity in vitro characterized on cancer cells such as gastric cancer and breast cancer [22,23], its function on reducing cancer growth is still minimal $[24,25]$. Additionally, in inflammation-related diseases, although the sivelestat could decrease the incidence of acute lung injury after surgery [26] and the AZD 9668 , another NE inhibitor, which has been proven to be able to improve lung function with bronchiectasis and reduce inflammatory markers in sputum for COPD patients [27], the benefit in acute lung injury and acute respiratory distress syndrome is still limited. In recent years, many novel orally available neutrophil elastase inhibitors have been designed and some have already entered phase II clinical trials for a variety of pulmonary diseases. MPH-966 significantly suppressed NE activity and reduced pro-inflammatory cytokines in a 5-FU-induced intestinal mucositis mouse model [28]. In a preclinical study, BAY-85-8501 proved to be able to prevent the development of lung injury and inflammation induced by NE in acute lung injury [29]. A phase I clinical study also showed a safety and tolerability profile in patients with non-cystic fibrosis bronchiectasis [30]. POL6014, a novel NE inhibitor developed for patients with cystic fibrosis, showed a safety and tolerability profile and a significant reduction in active NE after single dosing in a phase I clinical trial [31]. However, all these studies were designed for pulmonary diseases. We are not aware of any cancer-related studies.

In many cancer types, both the expression and activity of neutrophil elastase are upregulated. The number of neutrophils and the neutrophil to lymphocyte (N/L) ratio in peripheral blood is significantly higher in patients with lung cancer with or without COPD than in patients with COPD or healthy individuals. However, the cell count of neutrophils in BAL fluid is significantly lower in patients with lung cancer than in individuals with COPD. Notably, the NE level in serum and BAL fluid is five and threefold, respectively, greater in lung cancer patients compared to patients with COPD [14]. A strong NE proteolytic fingerprint was also found in the colon adenocarcinoma proteome [32], and elevated NE has a positive correlation with the poor response to trastuzumab therapy [33]. In summary, cancer is a potent inducer of NE. Nowadays, immunotherapy is considered to be a promising therapy in addition to traditional therapies, including chemotherapy, surgery, and radiotherapy. Antibody-based immunotherapy is attractive for cancer therapy for its high specificity, its high-affinity to the targets at nM levels, and the ability to activate effector functions elicited by the $F_{c}$ region. In recent decades, there has been a growing interest in pursuing antibody fragments and domains as therapeutics, including antigenbinding fragments ( $\mathrm{Fab}, 50 \mathrm{kDa})$, single-chain variable fragments ( $\mathrm{scFv}, 30 \mathrm{kDa})$, and $\mathrm{V}_{\mathrm{H}}$ (heavy-chain variable domain, $15 \mathrm{kDa}$ ) by the virtual of their smaller molecular sizes, and desirable pharmacokinetics in special clinical applications [34,35]. In addition, their low immunogenicity, high stability, and small size make the domain antibody much easier to infiltrate into cancer tissue and block the antigen inside the tumor.

The mechanism by which antibody-neutralizing enzymes may much differ from enzymatic inhibitors depends on the antibody-binding epitope. Firstly, same as enzyme inhibitors, an antibody can directly block the enzyme active site to inhibit enzyme activity [36,37]. Secondly, an antibody can interact with the adjacent regions of the active site to obstruct the access of substrates [38] or interact with other regions which could induce a conformational change and, thus, deactivating its catalytic activity [37]. In our current study, we identify potent NE monoclonal antibodies by panning our large human $\mathrm{V}_{\mathrm{H}}$ and 
Fab antibody phage libraries against recombinant neutrophil elastase. Several binders are screened and characterized for affinity and stabilities. Among these, Fab 1C10 and $\mathrm{V}_{\mathrm{H}} 1 \mathrm{D} 1.43$ with the IgG1 Fc fusion format show specificity against NE and have potent inhibition effects on enzyme activity. To our best knowledge, this is the first report of NE-specific antibodies as a new format of neutrophil elastase inhibitors with potential implications for immunotherapy on cancer and inflammatory diseases.

\section{Results}

\subsection{Selection of High-Affinity $V_{H}$ Domains and Fab Antibodies against Neutrophil Elastase}

We, previously, developed several large phage-displayed libraries using PBMC from non-immunized healthy donors [39,40]. In this study, two large phage-displayed human $\mathrm{V}_{\mathrm{H}}$ and Fab libraries were used for panning against recombinant NE protein, which fuses with the human IgG1 Fc tag due to the enhanced stability. After three rounds of panning, a panel of $\mathrm{VH}$ and Fab binders was screened. Among these binders, two high-affinity antibodies, termed as Fab 1C10 and $V_{H} 1 D 1$, were selected based on their high affinities and favorable biophysical properties. The $\mathrm{EC}_{50}$ of Fab $1 \mathrm{C} 10$ and $\mathrm{V}_{\mathrm{H}} 1 \mathrm{D} 1$ tested by ELISA were $16.3 \pm 0.52 \mathrm{nM}$ and $25.5 \pm 2.57 \mathrm{nM}$, respectively (Figure 1a). The equilibrium dissociation constant (KD) of these two binders (Fab 1C10 and $\mathrm{V}_{\mathrm{H}}$ 1D1) with recombinant human ELA2 measured by BLItz was $8.5 \mathrm{nM}$ and $69.7 \mathrm{nM}$, respectively (Table 1). To further improve the affinity of the $\mathrm{V}_{\mathrm{H}} 1 \mathrm{D} 1$ binder, we constructed a random mutant library by using errorprone PCR. After three rounds of panning against NE-Fc with kinetic selection by using the prototype $V_{H} 1 D 1$, one clone named $V_{H} 1 D 1.43$ was identified. The $E_{50}$ of $V_{H} 1 D 1.43$ tested by ELISA was $4.3 \pm 0.17 \mathrm{nM}$ (Figure 1a) and the equilibrium dissociation constant was $8.4 \mathrm{nM}, 5-10$-fold higher than that of the parental clone (Table 1). In addition, we evaluated the aggregation propensity of these binders by using dynamic light scattering (DLS) and size-exclusion chromatography (SEC). The $\mathrm{V}_{\mathrm{H}} 1 \mathrm{D} 1$ had both monomer and dimer forms, but after affinity maturation, the main form of $\mathrm{V}_{\mathrm{H}} 1 \mathrm{D} 1.43$ was a monomer measured by SEC (Figure 1b) and there was no obvious aggregation after a 7-day incubation at $37^{\circ} \mathrm{C}$ as measured by DLS (Figure 1d). Fab 1C10 was a monomer and had no high molecular weight form measured by SEC (Figure 1c). Even though Fab 1C10 showed a high molecular peak by DLS at $4{ }^{\circ} \mathrm{C}$, after the 7 -day incubation at $37^{\circ} \mathrm{C}$ at a concentration of $1 \mathrm{mg} / \mathrm{mL}$, there was no aggregation observed by DLS, indicating that the high molecular form was reversible and soluble (Figure 1d).

\subsection{Conversion of $V_{H}$ Domain and Fab Binders to $V_{H}-F c$ and $I g G 1$}

To increase the avidity and extend the in vivo half-life of $\mathrm{V}_{\mathrm{H}} 1 \mathrm{D} 1.43$ and Fab 1C10, these two binders were converted to a bivalent antibody by fusion to the human IgG1 Fc $\left(\mathrm{V}_{\mathrm{H}}-\mathrm{Fc} 1 \mathrm{D} 1.43\right.$ and IgG1 1C10). The $\mathrm{EC}_{50}$ of IgG1 $1 \mathrm{C} 10$ and $\mathrm{V}_{\mathrm{H}}-\mathrm{Fc}$ 1D1.43 tested by ELISA were $0.4 \pm 0.02 \mathrm{nM}$ and $0.66 \pm 0.03 \mathrm{nM}$, respectively (Figure 1a). The equilibrium dissociation constant (KD) of $\mathrm{V}_{\mathrm{H}}-\mathrm{Fc} 1 \mathrm{D} 1.43$ and IgG1 $1 \mathrm{C} 10$ measured by BLItz was $1.9 \mathrm{nM}$ and $0.14 \mathrm{nM}$, respectively (Figure 1e,f, Table 1). The forms of IgG $1 \mathrm{C} 10$ and $\mathrm{V}_{\mathrm{H}}-\mathrm{Fc} 1 \mathrm{D} 1.43$ were a monomer and had no high molecular weight species measured by SEC (Figure 1b,c). 
a

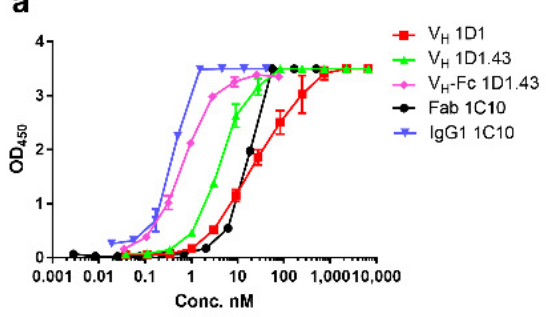

b

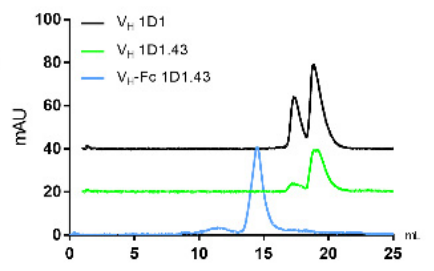

C

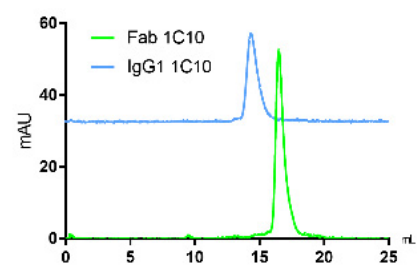

d

$V_{H} 1 D 1.43$

Fab $1 \mathrm{C} 10$
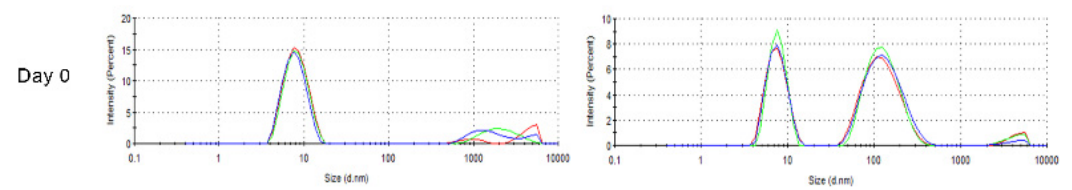

Day 7

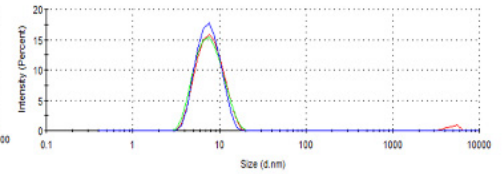

e

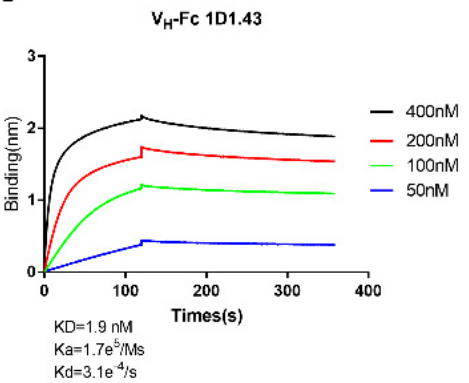

f

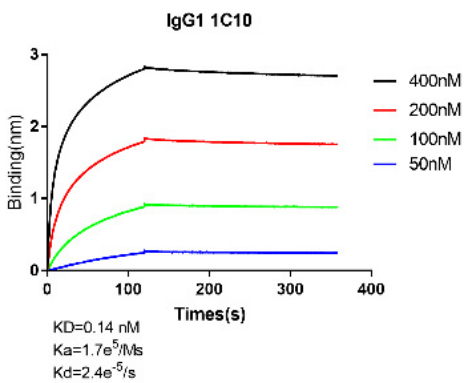

Figure 1. Binding and aggregation characterization of different format anti-hNE antibodies. (a) $\mathrm{V}_{\mathrm{H}}$ 1D1.43, Fab 1C10, $\mathrm{V}_{\mathrm{H}}-\mathrm{Fc}$ 1D1.43, and IgG1 1C10 binding to recombinant NE measured by ELISA. Experiments were performed in duplicate. (b) Aggregation evaluation of $\mathrm{V}_{\mathrm{H}} 1 \mathrm{D} 1, \mathrm{~V}_{\mathrm{H}}$ 1D1.43, and $\mathrm{V}_{\mathrm{H}}-\mathrm{Fc} 1 \mathrm{D} 1.43$ measured by SEC. (c) Aggregation evaluation of Fab $1 \mathrm{C} 10$ and IgG1 measured by SEC. (d) Aggregation evaluation of $\mathrm{V}_{\mathrm{H}}$ and Fab measured by DLS. Antibodies were evaluated at a concentration of $1 \mathrm{mg} / \mathrm{mL}$. (e,f) Kinetics of $\mathrm{V}_{\mathrm{H}}-\mathrm{Fc}_{\mathrm{C}} 1 \mathrm{D} 1.43(\mathbf{e})$ and IgG1 $1 \mathrm{C} 10$ (f) binding to recombinant NE measured by BLItz. Values were reported as the mean $\pm \mathrm{SD}$.

Table 1. Blitz results of human neutrophil elastase antibodies.

\begin{tabular}{|c|c|c|c|}
\hline Antibody & $k_{\text {on }}\left(M^{-1} s^{-1}\right)^{1}$ & $k_{o f f}\left(s^{-1}\right)^{1}$ & $\mathrm{KD}(\mathrm{nM})^{1}$ \\
\hline $\mathrm{V}_{\mathrm{H}} 1 \mathrm{D} 1$ & $5.9 \times 10^{4}$ & $4.1 \times 10^{-3}$ & 69.7 \\
\hline $\mathrm{V}_{\mathrm{H}} 1 \mathrm{D} 1.43$ & $7.2 \times 10^{4}$ & $6 \times 10^{-4}$ & 8.4 \\
\hline $\mathrm{V}_{\mathrm{H}}-\mathrm{Fc}_{\mathrm{c}} 1 \mathrm{D} 1.43$ & $1.7 \times 10^{5}$ & $3.1 \times 10^{-4}$ & 1.9 \\
\hline Fab 1C10 & $4.9 \times 10^{4}$ & $4.1 \times 10^{-4}$ & 8.5 \\
\hline IgG1 1C10 & $1.7 \times 10^{5}$ & $2.4 \times 10^{-5}$ & 0.14 \\
\hline
\end{tabular}

$\overline{{ }^{1} \text { Mean kinetic rate constants }\left(\mathrm{k}_{\text {on }}, \mathrm{k}_{\text {off }}\right) \text { and equilibrium dissociation constants }\left(\mathrm{KD}=\mathrm{k}_{\text {off }} / \mathrm{k}_{\text {on }}\right) \text { were determined }}$ from curve fitting analyses of BLItz results.

\subsection{Specificity of $V_{H}$ Domain and Fab Binders with Human NE}

To further test the specificity of these two $\mathrm{V}_{\mathrm{H}}$ domain and Fab binders, we tested the binding effects with recombinant human myeloperoxidase protein (rhMPO) and Proteinase 3 (PR3), both of which were released by neutrophils. The ELISA results showed that Fab $1 \mathrm{C} 10$ and $\mathrm{V}_{\mathrm{H}}$ 1D1.43 specifically bound to $\mathrm{NE}$ and did not bind to other enzymes 
released by neutrophils (Figure 2a,b). We further tested the specificity of IgG1 1C10 and $\mathrm{V}_{\mathrm{H}}-\mathrm{Fc} 1 \mathrm{D} 1.43$ by the detection of binding to BSA; the results showed that the binders had no non-specific binding with other proteins (Figure 2c,d).

a
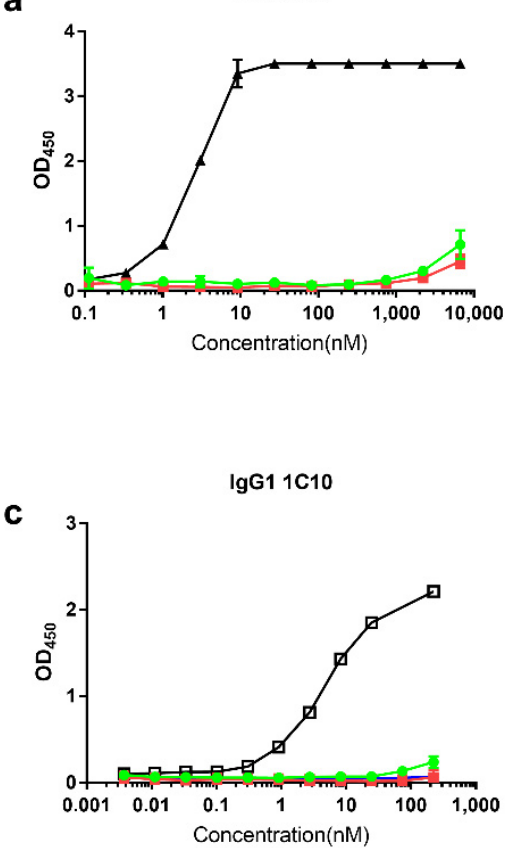

b
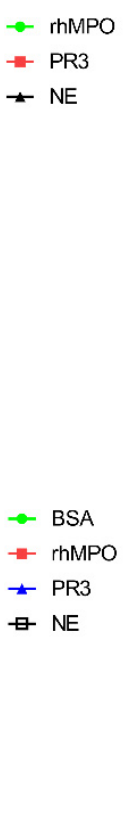

$\mathrm{V}_{\mathrm{H}} 1 \mathrm{D} 1.43$
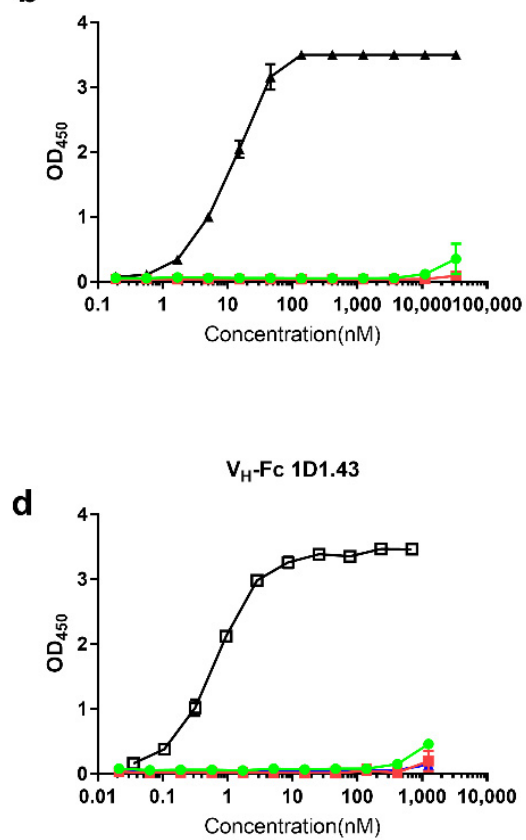

$\rightarrow$ rhMPO

$\rightarrow$ PR3

$\star \mathrm{NE}$

Figure 2. Specificity of $\mathrm{V}_{\mathrm{H}} / \mathrm{V}_{\mathrm{H}}-\mathrm{Fc}$ and Fab/IgG1 with recombinant human NE. (a,b) Binding of Fab $1 \mathrm{C} 10$ (a) and $\mathrm{V}_{\mathrm{H}}$ $1 \mathrm{D} 1.43$ (b) to rhNE, rhMPO, and PR3 measured by ELISA. (c,d) Binding of IgG1 1C10 (c) and $\mathrm{V}_{\mathrm{H}}-\mathrm{Fc} 1 \mathrm{D} 1.43$ (d) to rhNE, rhMPO, BSA, and PR3 measured by ELISA. rhNE, rhMPO, BSA, and PR3 were coated in 96-well microplates at $50 \mathrm{ng} /$ well. Experiments were performed in duplicate. Values were reported as the mean $\pm \mathrm{SD}$.

\subsection{Inhibition on NE Enzyme Activity and Function}

To study the function of the binders, we tested the inhibition effect on neutrophil elastase enzyme activity. The estimated $\mathrm{IC}_{50}$ of $\mathrm{V}_{\mathrm{H}} 1 \mathrm{D} 1.43$ was about $60 \mathrm{uM}$, but after converting to the $\mathrm{V}_{\mathrm{H}}-\mathrm{Fc}$ form, the $\mathrm{IC}_{50}$ was $5.3 \pm 1.2 \mathrm{uM}$, a 10-fold elevation compared to the $\mathrm{V}_{\mathrm{H}}$ form (Figure 3a,c). Additionally, the estimated $\mathrm{IC}_{50}$ of Fab $1 \mathrm{C} 10$ was about $5 \mathrm{uM}$, and after converting to IgG1, the $\mathrm{IC}_{50}$ was elevated to $1.8 \pm 0.9 \mathrm{uM}$ (Figure $3 \mathrm{~b}, \mathrm{~d}$ ). In addition, we also tested the effects of binders on the uptake of NE by cancer cells as $\mathrm{NE}$ needs to enter the cytoplasm to stimulate cell proliferation. First, we tested the uptake ability of three different cancer cells on NE, the result showing that, compared with the A549 cell and SK-BR-3 cell, PC-3 showed the highest ability to uptake NE (data not shown). To test the block function of binders on NE uptake by cancer cells, we incubated IgG1 1C10 and $\mathrm{V}_{\mathrm{H}}-\mathrm{Fc} 1 \mathrm{D} 1.43$ with $\mathrm{NE}$ at room temperature for $20 \mathrm{~min}$, separately, then added the mixture to a PC-3 tumor cell followed with another $24 \mathrm{~h}$ incubation. The results showed that both IgG1 $1 \mathrm{C} 10$ and $\mathrm{V}_{\mathrm{H}}-\mathrm{Fc}$ 1D1.43 could significantly decrease the NE uptake by cancer cells (Figure 4) and the inhibition abilities were comparable. As NE plays a similar role in fibroblast proliferation, we tested whether NE binders could inhibit the fibroblast differentiation promoted by NE. The wound-healing assay showed that the NE treatment could facilitate the wound closure and the function of the NE was inhibited by IgG1 1C10 and $\mathrm{V}_{\mathrm{H}}-\mathrm{Fc}$ 1D1.43, and the ratio of NE-Abs for inhibiting the differentiation of the fibroblast induced by NE was about 1:1.25 (Figure 5). These results suggested that IgG1 1C10 and $\mathrm{V}_{\mathrm{H}}-\mathrm{Fc}$ 1D1.43 are potent antibody-based inhibitors of neutrophil elastase and are very promising in novel therapy for cancer and inflammatory-related diseases. 

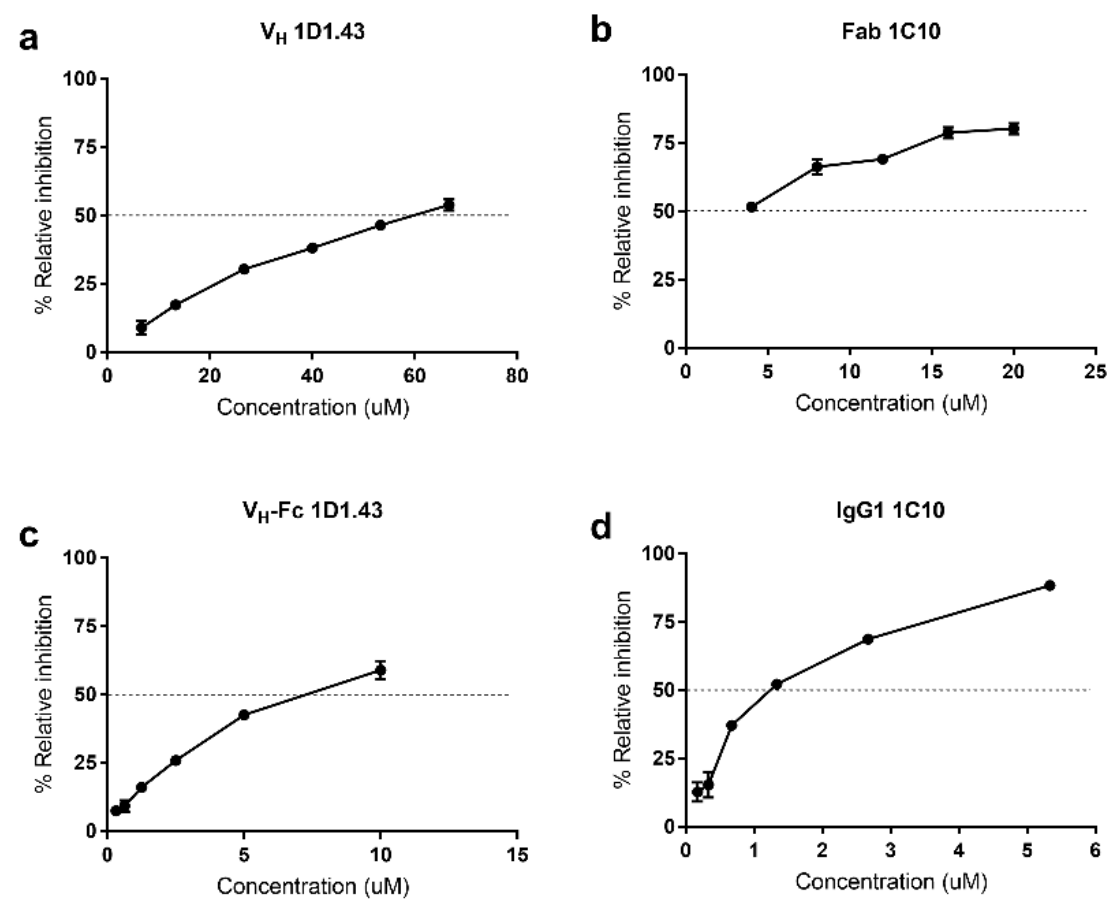

Figure 3. Inhibition effects of $\mathrm{V}_{\mathrm{H}} / \mathrm{V}_{\mathrm{H}}-\mathrm{Fc}_{\mathrm{C}} 1 \mathrm{D} 1.43$ and $\mathrm{Fab} / \mathrm{IgG} 1 \mathrm{C} 10$ on enzyme activity. (a,c) Inhibition of $\mathrm{V}_{\mathrm{H}} 1 \mathrm{D} 1.43$ (a) and $\mathrm{V}_{\mathrm{H}}-\mathrm{Fc}$ 1D1.43 (c) on NE enzyme activity. (b,d) Inhibition of Fab 1C10 (b) and IgG1 1C10 (d) on NE enzyme activity. Each experiment was performed in duplicate. Calculation: choose two time points (T1 and T2) in the linear range, determine the Fluorescence (FLU) at each time (FLU1 and FLU2) and use them to determine the Slope. Slope $=($ FLU2 - FLU1 $) /(T 2-\mathrm{T} 1)=\Delta$ FLU $/$ minute. \%Relative inhibition $=\left(\right.$ Slope $_{\mathrm{EC}}-$ Slope $\left._{\mathrm{SM}}\right) /$ Slope $_{\mathrm{EC}} \times 100 \%$; $_{\text {Slope }}=$ the slope of the Sample inhibitor and Slope $\mathrm{SM}_{\mathrm{EM}}=$ the slope of the Enzyme control. Values were reported as the mean $\pm \mathrm{SD}$.

a
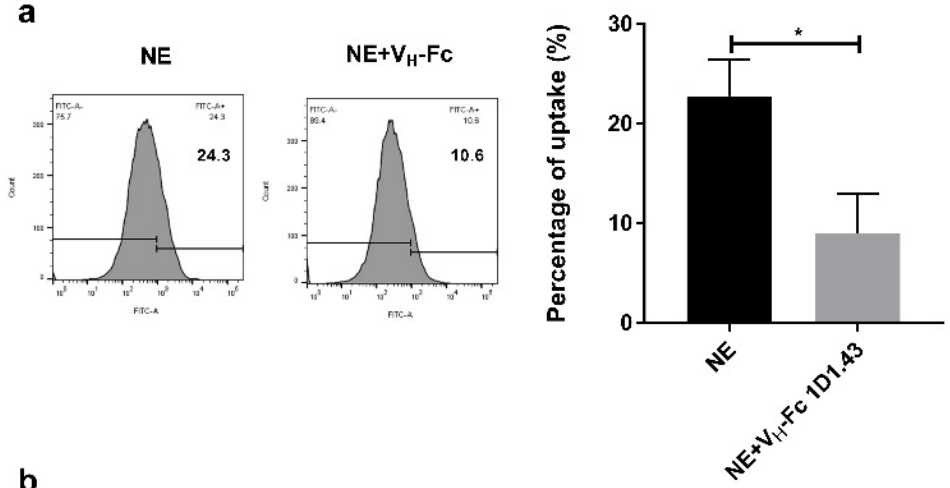

b
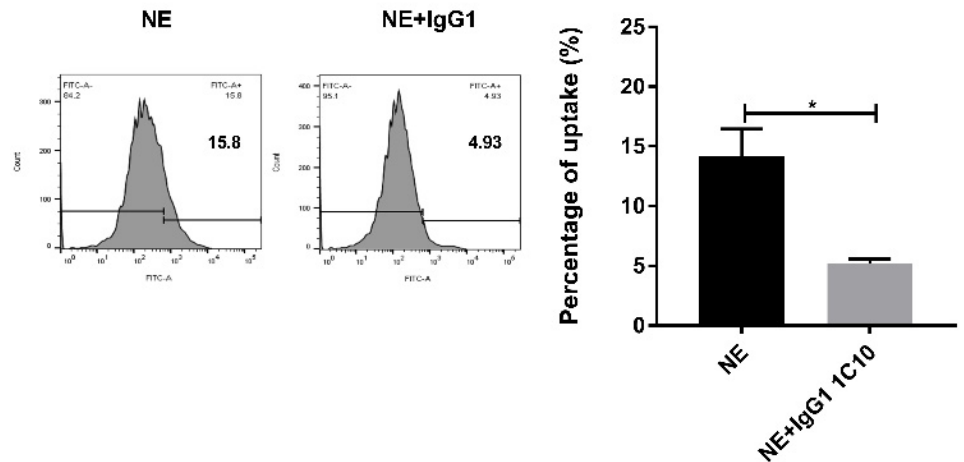

Figure 4. $\mathrm{V}_{\mathrm{H}}$-Fc 1D1.43 and IgG1 1C10 inhibited NE uptaking by tumor cell. (a,b) Inhibition of VH-Fc 1D1.43 (a) and IgG1 1C10 (b) on NE uptaking by PC-3 tumor cell measured by flow cytometry. 
PC-3 cells were plated in a 24-well plate and incubated with serum-free medium for $24 \mathrm{~h}$, then treated with $30 \mathrm{nM}$ NE-FITC with or without $100 \mathrm{nM}$ antibody proteins for $1 \mathrm{~h}$. Experiments were performed in duplicate; unpaired Student's $t$-test, ${ }^{*} p<0.05$. Values were reported as the mean $\pm \mathrm{SD}$.

a
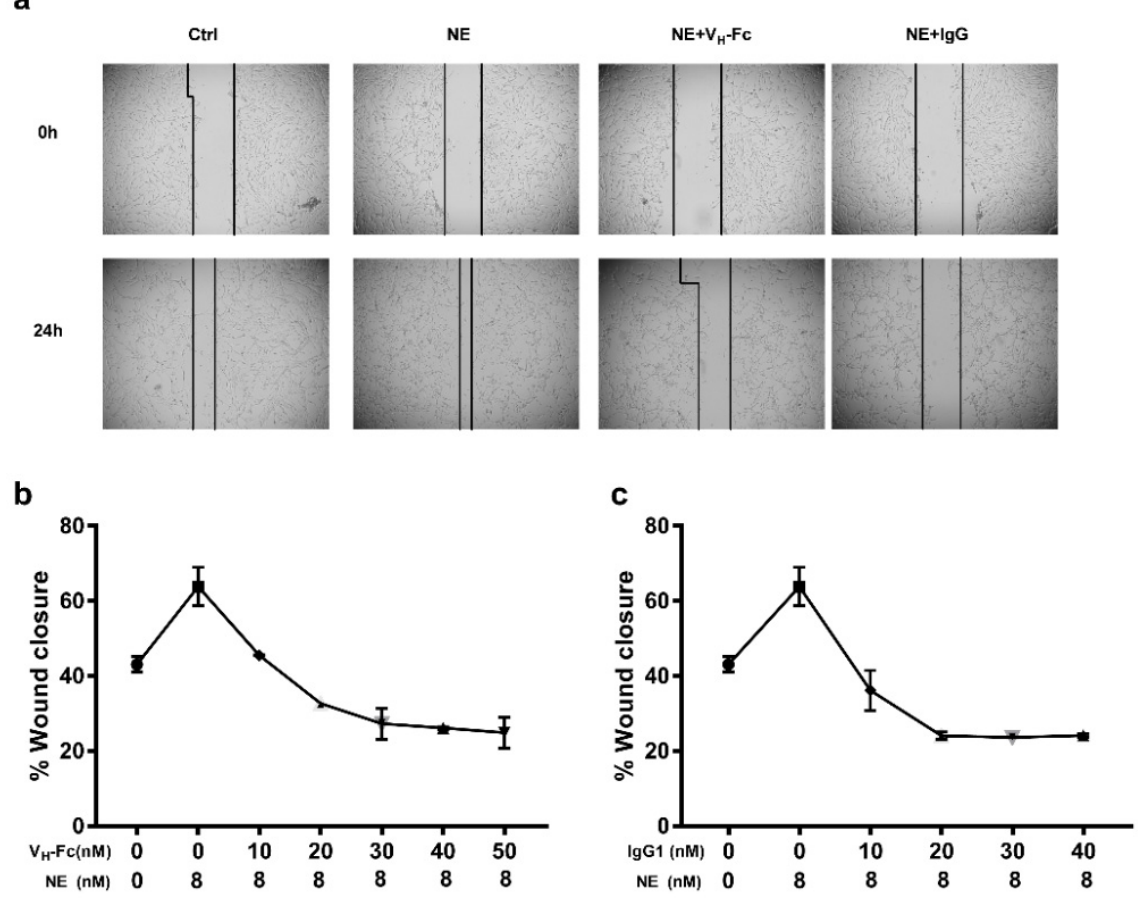

Figure 5. $\mathrm{V}_{\mathrm{H}}-\mathrm{Fc}$ 1D1.43 and IgG1 $1 \mathrm{C} 10$ inhibited NE-promoted fibroblast differentiation. (a) Representative pictures of wound-healing assay. LL47 fibroblasts were plated into a 24-well plate and scratched, treated with $8 \mathrm{nM} \mathrm{NE}$ with or without antibody proteins at different concentrations for 24 h. (b,c) $V_{\mathrm{H}^{-}}$Fc 1D1.43 (b) and IgG1 $1 \mathrm{C} 10$ (c) inhibited NE-promoted LL 47 fibroblast differentiation. Experiments were performed in duplicate. Values were reported as the mean of percent wound closure \pm SD.

\subsection{Epitope Mapping of IgG1 $1 C 10$ and $V_{H}-F c 1 D 1.43$}

To test the binding epitope of IgG1 $1 \mathrm{C} 10$ and $\mathrm{V}_{\mathrm{H}}-\mathrm{Fc}$ 1D1.43, the competition Blitz and peptide array-based conformational epitope mapping was performed. We tested the competition effects of IgG1 $1 \mathrm{C} 10$ and $\mathrm{V}_{\mathrm{H}}-\mathrm{Fc} 1 \mathrm{D} 1.43$ for binding to human NE by BLItz (Figure 6a); it showed that IgG1 $1 \mathrm{C} 10$ and $\mathrm{V}_{\mathrm{H}}$-Fc 1D1.43 did not compete with each other, suggesting that the epitope of these two binders is different and this was confirmed by the conformational epitope mapping (Figures $6 \mathrm{~b}$ and S1). The conformational epitope mapping result showed that IgG1 1 C10 had the antibody response against epitope-like spot patterns formed by adjacent lengths with the consensus motifs RPHAWPF, VRVVLGAHNLSRR, FENGYD, and VQVAQLPAQGRR at all peptide lengths. However, the interactions with peptides with the consensus motifs VRVVLGAHNLSRR, VQVAQLPAQGRR, and RRSNVCTLVRGR likely resulted from a non-specific ionic antibody binding due to shorter basic RR or RGR motifs in these consensus motifs. Additionally, motif RPHAWPF showed clearer spot morphologies than motif FENGYD (Supplementary Figure S1a). Therefore, we predicted that IgG1 1C10 bound to an epitope motif of 'RPHAWPF', which was located at the connecting hinge region of NE S1 and S2 subsites and was distal from the NE active site as defined by the catalytic triad (H57-D102-S195) (Figure 6c), indicating that the inhibition effects of IgG1 1C10 on NE may have been triggered by the NE conformational change upon its binding. By contrast, $\mathrm{V}_{\mathrm{H}}-\mathrm{Fc}$ 1D1.43 showed a high antibody response to the 'IFENGYD' motif at all peptide lengths, which was adjacent to the active site (Figures $6 \mathrm{~d}$ and S1b), 
indicating that the inhibition effect of $\mathrm{V}_{\mathrm{H}}-\mathrm{Fc}$ 1D1.43 may have been due to directly blocking the accession of the substrate to the active site.

a

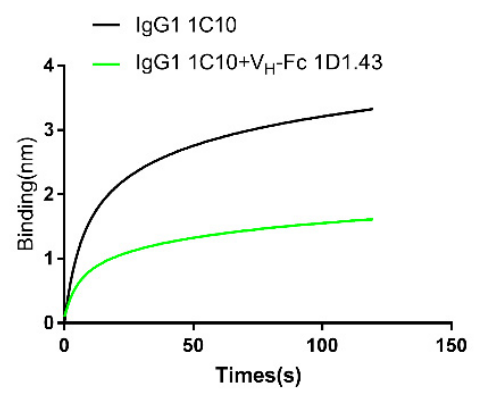

C

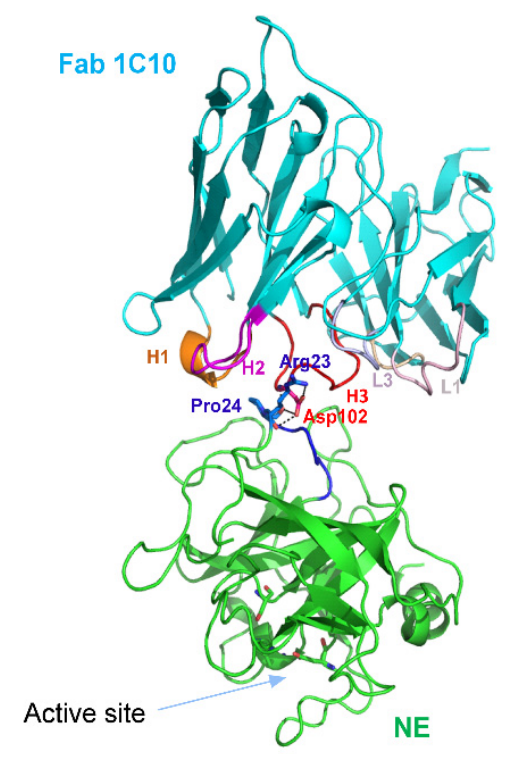

b

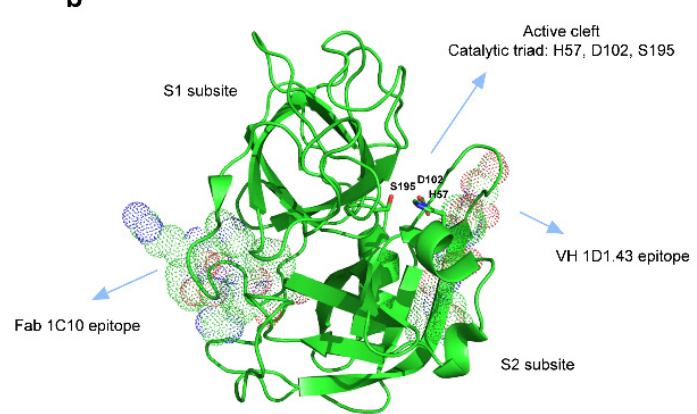

d

Figure 6. Epitope mapping of $\mathrm{V}_{\mathrm{H}}-\mathrm{Fc} 1 \mathrm{D} 1.43$ and IgG1 $1 \mathrm{C} 10$ by using conformational epitope mappings. (a) Competition between $\mathrm{V}_{\mathrm{H}}-\mathrm{Fc} 1 \mathrm{D} 1.43$ and IgG1 $1 \mathrm{C} 10$ measured by BLItz. (b) The binding region of $\mathrm{V}_{\mathrm{H}} 1 \mathrm{D} 1.43$ and Fab $1 \mathrm{C} 10$ on hNE (PDB: 3Q76) based on the conformational epitope mapping results with the binding motifs highlighted by dot presentations. The enzymatic sites are shown by the stick models. (c,d) The detailed binding model of Fab $1 \mathrm{C} 10$ and $\mathrm{V}_{\mathrm{H}} 1 \mathrm{D} 1.43$ on hNE, as predicted by Z-DOCK programs. Human NE is represented as green cartoons with active site highlighted by sticks and binding epitope highlighted by blue color. Fab $1 \mathrm{C} 10$ and $\mathrm{V}_{\mathrm{H}} 1 \mathrm{D} 1.43$ are represented as cyan cartoons with highlighted colored CDR loops.

\section{Discussion}

NE was mostly reported to cause tissue damage and alter the extracellular matrix remodeling process in many lung-related inflammation diseases such as acute lung injury, pneumonia, and COPD. In addition, researchers have demonstrated that NE could induce fibroblast differentiation, which is correlated with lung fibrosis [41]. More recently, several reports showed that the high expression and activity of NE are related to cancer progressions such as Lung cancer, breast cancer, and prostate cancer. NE could directly promote cellular proliferation by targeting IRS-1, which activates the PI3K proliferation pathway both in fibroblasts and lung cancer cells [42]. Antibody-based therapy is a very efficient and promising treatment for cancer and, approximately, 30 therapeutic monoclonal antibodies have been approved by the FDA over recent decades. Moreover, there are many other ways that mAbs can be employed in cancer treatment such as targeting pro-tumorigenic molecules in the tumor microenvironment and antibody-drug conjugates (ADC). 
In this study, we demonstrated and characterized two fully human anti-NE antibodies, $\mathrm{V}_{\mathrm{H}} 1 \mathrm{D} 1.43$ and Fab 1C10, with a high-affinity of KD in the nanomolar range. These two antibodies exhibited good properties on aggregation resistance. $\mathrm{V}_{\mathrm{H}} 1 \mathrm{D} 1.43$ showed a good developability as its stability at a high concentration after a long incubation at $37^{\circ} \mathrm{C}$ without shaking (static standard incubation) and low aggregation. As for Fab 1C10, even though it showed an aggregation at $4{ }^{\circ} \mathrm{C}$, such an aggregation disappeared after a $37{ }^{\circ} \mathrm{C}$ incubation at a high concentration. The reason for this reversible phenomenon may have been due to the temperature change during the purification process and this was recovered during the $37{ }^{\circ} \mathrm{C}$ incubation (Figure 1). Moreover, these two antibodies were able to specifically bind to human neutrophil elastase and did not bind to BSA, MPO, nor PR3 (Figure 2), indicating a low potential off-target toxicity for in vivo use. After converting to $\mathrm{V}_{\mathrm{H}}$-Fc and IgG1, the avidities of these two antibody were elevated about 4-fold and 60-fold separately (Figure 1). The two antibodies were fully human; therefore, they likely were less immunogenic and could be much safer than chemical inhibitors.

The function of NE on cancer cell proliferation happens after it entry into the cancer cell cytoplasm and cleavage the IRS-1 to active the PI3K-AKT proliferation pathway. Therefore, the strategy of antibody therapy against NE is either by blocking the cancer cell uptake or inhibiting enzyme activity. We tested the inhibition of the two antibodies on enzyme activity; the $\mathrm{V}_{\mathrm{H}}-\mathrm{Fc} 1 \mathrm{D} 1.43$ antibody showed a similar $\mathrm{IC}_{50}$ level compared with the positive inhibitor SPCK, and IgG1 1C10 showed a 2.6-fold higher level than a positive inhibitor. Both antibodies showed the block effect on the cancer cell uptake at the 1:3 NE-Abs ratio (Figure 4). The wound healing experiment also showed that these two antibodies could inhibit the differentiation of a fibroblast, which was promoted by NE at the 1:1.25 NE-Abs ratio (Figure 5). These results suggested that $\mathrm{V}_{\mathrm{H}}-\mathrm{Fc}$ 1D1.43 and IgG1 1C10 could be promising antibodies for antibody therapy in cancer and inflammatory diseases.

We did not localize the antibodies epitope by the X-ray method, as the hNE-antibody complex was found hard to form the crystal. Instead, we conducted competition BLItz and conformational epitope mapping to predict the binding site of $\mathrm{V}_{\mathrm{H}^{-}} \mathrm{Fc}$ 1D1.43 and IgG1 1C10 with hNE. The predicted epitope motif of IgG1 $1 \mathrm{C} 10$ was "RPHAWPF" and V $\mathrm{H}_{\mathrm{H}} 1 \mathrm{D} 1.43$ was "IFENGYD" (Figure 6). As the epitope of IgG1 1C10 was not near the enzyme active site, the possible mechanism of inhibiting the NE function by IgG1 1C10 was that IgG1 $1 \mathrm{C} 10$ binding to $\mathrm{hNE}$ induced the change of NE conformation and caused it to lose its catalytic activity. On the contrary, the binding site of $\mathrm{V}_{\mathrm{H}}-\mathrm{Fc} 1 \mathrm{D} 1.43$ was located at adjacent regions of the NE active site, so it could directly obstruct the access of the substrate and inhibit NE activity. By comparing the two antibodies functions, IgG1 1C10 was better than $\mathrm{V}_{\mathrm{H}}-\mathrm{Fc}$ 1D1.43, which indicated that changing NE conformation may be better than directly blocking the active site by inhibiting the NE function.

In conclusion, we identified two fully human antibodies, the $\mathrm{V}_{\mathrm{H}}$ domain and Fab fragment, that showed a high-affinity and specificity to human neutrophil elastase. The potent inhibition of NE enzyme activity and blocking effects on the NE uptake by cancer cell and fibroblast differentiation makes them promising immunotherapy candidates for cancer and inflammatory diseases.

\section{Materials and Methods}

\subsection{Protein Expression and Purification (E. coli and Expi 293 Cell)}

The ELANE gene was synthesized by IDT (Coralville, IA, USA), then cloned into pSecTag expression vector, which fused with human IgG1 Fc. For the conversion of IgG1 from Fab, the heavy chain and light chain of Fab were amplified and re-cloned into the pcDNA-IgG1 vector. For transient expression, the plasmid was transfected into Expi293 cells by PEI, and purified by Protein A resin (GenScript, Piscataway, NJ, USA). The expression and purification of $\mathrm{V}_{\mathrm{H}}$ and Fab binders were performed in E. coli Top10F' bacterial with $1 \mathrm{mM}$ IPTG induction at $30{ }^{\circ} \mathrm{C}$ for $16 \mathrm{~h}$. Bacterial pellets were lysed by Polymyxin B (Sigma-Aldrich, St. Louis, MO, USA) and the supernatant was loaded on Ni-NTA column (GE Healthcare, Chicago, IL, USA) for purification. 


\subsection{Panning and Screening from Two Large Phage Libraries}

To select antibodies against neutrophil elastase, two large $\mathrm{V}_{\mathrm{H}}$ and $\mathrm{Fab}$ phage libraries were used for panning separately. Briefly, $10 \mu \mathrm{g}$ NE-Fc was coated in 96-well Protein G microplate in PBS at $4{ }^{\circ} \mathrm{C}$ overnight. Blocking coated the Protein G plate and phage library with $5 \%$ milk for $1 \mathrm{~h}$ at room temperature, then phage library was added into NE-Fc-coated Protein $\mathrm{G}$ plate and incubated at room temperature for $1 \mathrm{~h}$, and then washed by PBST. After washing, phages were eluted by $0.1 \mathrm{M}, \mathrm{PH} 3$ Glycine, and neutralized with $1 \mathrm{M}, \mathrm{PH} 8$ Tris- $\mathrm{HCl}$. For the second and third round panning, $5 \mu \mathrm{g}$ and $2.5 \mu \mathrm{g}$ of NE-Fc were used as antigen. After the third round panning, 192 individual clones were screened for binding with NE-His protein by soluble phage ELISA and 11 unique Fab and $4 \mathrm{~V}_{\mathrm{H}}$ were identified.

\subsection{Size-Exclusion Chromatography (SEC)}

The purity and structure of the antibodies were analyzed by Superdex 200 Increase 10/300 GL chromatography (GE Healthcare, Chicago, IL, USA). The standard proteins used for calibration and their molecular weights were: Ferritin $\left(\mathrm{M}_{\mathrm{r}} 440 \mathrm{kDa}\right)$, Aldolase $\left(\mathrm{M}_{\mathrm{r}} 158 \mathrm{kDa}\right)$, Conalbumin $\left(\mathrm{M}_{\mathrm{r}} 75 \mathrm{kDa}\right)$, Ovalbumin $\left(\mathrm{M}_{\mathrm{r}} 44 \mathrm{kDa}\right)$, Carbonic anhydrase $\left(\mathrm{M}_{\mathrm{r}} 29 \mathrm{kDa}\right)$, and Ribonuclease A $\left(\mathrm{M}_{\mathrm{r}} 13.7 \mathrm{kDa}\right)$ at $3 \mathrm{mg} / \mathrm{mL}$. A $500 \mu \mathrm{L}$ sample mix containing above proteins was loaded to the column and separated by the ÄKTA explorer machine (GE Healthcare, Chicago, IL, USA). For the antibody analysis, $100 \mu \mathrm{L}$ of filtered antibodies $(2 \mathrm{mg} / \mathrm{mL}$ ) in $1 \times$ DPBS (Dulbecco's phosphate-buffered saline, Gibco, Waltham, MA, USA) was analyzed. Antibodies were eluted by DPBS buffer at a flow rate of $0.5 \mathrm{~mL} / \mathrm{min}$.

\subsection{Dynamic Light Scattering (DLS)}

The aggregation resistance of $\mathrm{V}_{\mathrm{H}} 1 \mathrm{D} 1.43$ and Fab $1 \mathrm{C} 10$ was measured by dynamic light scattering (DLS). The buffer was changed to DPBS and filtered by a $0.22 \mu \mathrm{m}$ filter. The antibody concentration was adjusted to $1 \mathrm{mg} / \mathrm{mL}$. In total, a $500 \mu \mathrm{L}$ antibody sample was incubated at $37^{\circ} \mathrm{C}$ without shaking. On day 0 and day 7, samples were taken for DLS measurements on Zetasizer Nano ZS ZEN3600 (Malvern Instruments Limited, Westborough, MA, USA) to determine the antibody size distribution.

\subsection{Enzyme-Linked Immunosorbent Assay (ELISA)}

NE protein was coated in 96-well microplates at $50 \mathrm{ng} /$ well in PBS at $4{ }^{\circ} \mathrm{C}$ overnight and blocking with $5 \%$ milk in PBS for $2 \mathrm{~h}$ at room temperature. For the soluble Fab $/ \mathrm{V}_{\mathrm{H}}$ binding assay, the 3-fold serially diluted $\mathrm{Fab} / \mathrm{V}_{\mathrm{H}}$ were added and incubated for $1 \mathrm{~h}$ at $37^{\circ} \mathrm{C}$ and further incubated with anti-FLAG M2-peroxidase (HRP) antibody (A8592, SigmaAldrich, St. Louis, MO, USA) for another $1 \mathrm{~h}$. For the IgG1 binding assay, HRP-conjugated goat anti-human IgG1 Fc (Sigma-Aldrich, St. Louis, MO, USA) was used for detection. Finally, the reaction was developed by 3,3',5,5'-tetramethylbenzidine (TMB, Sigma-Aldrich, St. Louis, MO, USA) and was stopped by TMB stop buffer (ScyTek Laboratories, Logan, UT, USA) and recording absorbance at $450 \mathrm{~nm}$. The experiment was performed in duplicate.

\subsection{BLItz}

The affinity and avidity of the anti-hNE antibody were detected by biolayer interferometry BLItz (ForteBio, Menlo Park, CA, USA). Briefly, Dulbecco's PBS (DPBS) was used to establish baseline for $30 \mathrm{~s}$, and streptavidin biosensor (ForteBio) was coated with $16.7 \mathrm{ug} / \mathrm{mL}$ recombinant NE-Biotin for $2 \mathrm{~min}$. Different doses of Fab and IgG1 were used for association and monitored for $2 \mathrm{~min}$ to measure the affinity and avidity. Antigen-coated biosensors with PBS were served as reference control. The dissociation was monitored in DPBS for $4 \mathrm{~min}$.

\subsection{Enzyme Activity Inhibition Assay}

The inhibition effects of antibodies on enzyme activity were determined by an Elastase Inhibitor Screening Kit (Sigma-Aldrich). Briefly, antibodies were diluted to the desired concentration by assay buffer, then $50 \mu \mathrm{L}$ of neutrophil elastase solution was added and 
incubated at $37{ }^{\circ} \mathrm{C}$ for $45 \mathrm{~min}$. The SPCK NE inhibitor was used as positive control. After incubation, $25 \mu \mathrm{L}$ of substrate solution was added to each reaction well and the fluorescence was measured in kinetic mode for $30 \mathrm{~min}$. The result was calculated by \%Relative inhibition.

\subsection{Cells and Flow Cytometry}

The human prostate adenocarcinoma cell line PC-3 was purchased from ATCC. Additionally, the cells were maintained in F-12k medium plus $10 \%$ FBS and 1\% penicillin/streptomycin. Cells were seeded at a concentration of $1 \times 10^{5}$ cells/well in a 24 -well plate and allowed to adhere overnight and were then incubated in serum-free medium for $24 \mathrm{~h}$. Neutrophil elastase was labeled with FITC by a FITC protein labeling kit (Thermo Fisher, Waltham, MA, USA) according to the manufacturer's instruction. Cells were treated with $30 \mathrm{nM}$ NE-FITC with or without $100 \mathrm{nM}$ binders for $1 \mathrm{~h}$; then, the cells were analyzed by flow cytometry (BD Bioscience, San Jose, CA, USA). The data were analyzed using FlowJo Software.

\subsection{Wound Healing Assay}

LL 47 fibroblast cells were seeded into 24-well plate and grown to confluence in complete F-12K medium. After being starved for $1 \mathrm{~h}$ in serum-free medium, the cells were wounded with $200 \mu \mathrm{L}$ pipet tips, washed with PBS, and treated with NE with or without binders at different doses for $24 \mathrm{~h}$. Images were captured under a $4 \times$ objective microscope (Olympus microscope, Westborough, MA, USA). Wound areas were quantified by using Image J software.

\subsection{Conformational Epitope Mappings}

Conformational epitope mapping was proceeded by PEPperPRINT GmbH (Heidelberg, Germany). Briefly, the sequence of hNE was elongated with neutral GSGSGSG linkers at the C-and N-termini. The elongated antigen sequence was converted into 7, 10, and 13 amino acid peptides with peptide-peptide overlaps of 6,9 , and 12 amino acids. Human antibodies IgG1 $1 \mathrm{C} 10$ and $\mathrm{V}_{\mathrm{H}}-\mathrm{Fc} 1 \mathrm{D} 1.43$ at a concentration of $10 \mu \mathrm{g} / \mathrm{mL}$ and $30 \mu \mathrm{g} / \mathrm{mL}$ were incubated with antigen peptides for $16 \mathrm{~h}$ at $4{ }^{\circ} \mathrm{C}$, followed by goat anti-human $\operatorname{IgG}$ DyLight680 incubation for $45 \mathrm{~min}$ at room temperature. The result was read by Innopsys InnoScan 710-IR Microarray Scanner.

\subsection{Molecular Docking for Predicting Binding Models of Fab $1 C 10$ and VH 1D1.43}

Fab 1C10 and VH 1D1.43 structures were modeled in SWISS-MODEL [43,44], followed by energy minimization. Z-DOCK program was used for docking Fab $1 \mathrm{C} 10$ and $\mathrm{VH}$ 1D1.43 onto NE, whose structure was resolved as (PDB: 3Q76). The antibody binding and blocking regions on NE were based on the experimental epitope mapping results. Z-DOCK output the top 10 optimal poses, which were visually scrutinized for interaction interface compatibility and side-chain clashes, with selections of the most favorable pose as the binding models. The structural figures were prepared by PyMol 2.5.

\subsection{Statistical Analysis}

Statistical analyses, including $\mathrm{EC}_{50}$ and $\mathrm{IC}_{50}$, were performed by GraphPad Prism. Experiments were repeated a minimum of three times. Differences were considered statistically significant when $p<0.05$.

Supplementary Materials: The following are available online at https:/ /www.mdpi.com/article/10 .3390/ijms222011136/s1.

Author Contributions: D.S.D., S.D.S., J.W.M. and X.C. conceived and designed the research; X.C. identified and characterized antibodies; Z.S. and D.-S.B. created the phage libraries; W.L. analyzed the epitope of antibodies picture; D.S.D. and X.C. wrote the draft of the article. All authors have read and agreed to the published version of the manuscript. 
Funding: This research and the APC was funded by the UPMC.

Institutional Review Board Statement: Not applicable.

Informed Consent Statement: Not applicable.

Data Availability Statement: The data presented in this study are available upon request from the corresponding author.

Acknowledgments: We would like to thank the members of the Center for Antibody Therapeutics, Dontcho Jelev, Chuan Chen, Cynthia Adams, and Ye-Jin Kim for their helpful discussions. This work was supported by the UPMC.

Conflicts of Interest: X.C., Z.S., D.-S.B., S.D.S., J.W.M. and D.S.D. are co-inventors of a patent, submitted by the University of Pittsburgh, related to the antibodies described in this paper.

\section{References}

1. Taylor, S.; Dirir, O.; Zamanian, R.T.; Rabinovitch, M.; Thompson, A.A.R. The Role of Neutrophils and Neutrophil Elastase in Pulmonary Arterial Hypertension. Front. Med. 2018, 5, 217. [CrossRef]

2. Brostjan, C.; Oehler, R. The role of neutrophil death in chronic inflammation and cancer. Cell Death Discov. 2020, 6, 26. [CrossRef]

3. Kolaczkowska, E.; Kubes, P. Neutrophil recruitment and function in health and inflammation. Nat. Rev. Immunol. 2013, 13, 159-175. [CrossRef]

4. Witter, A.R.; Okunnu, B.M.; Berg, R.E. The Essential Role of Neutrophils during Infection with the Intracellular Bacterial Pathogen Listeria monocytogenes. J. Immunol. 2016, 197, 1557-1565. [CrossRef]

5. $\quad$ Lonergan, M.; Dicker, A.J.; Crichton, M.L.; Keir, H.R.; Van Dyke, M.K.; Mullerova, H.; Miller, B.E.; Tal-Singer, R.; Chalmers, J.D. Blood neutrophil counts are associated with exacerbation frequency and mortality in COPD. Respir. Res. 2020, 21, 166. [CrossRef]

6. Conese, M.; Copreni, E.; Di Gioia, S.; De Rinaldis, P.; Fumarulo, R. Neutrophil recruitment and airway epithelial cell involvement in chronic cystic fibrosis lung disease. J. Cyst. Fibros 2003, 2, 129-135. [CrossRef]

7. Yang, S.C.; Tsai, Y.F.; Pan, Y.L.; Hwang, T.L. Understanding the role of neutrophils in acute respiratory distress syndrome. Biomed. J. 2020, 44, 439-446. [CrossRef] [PubMed]

8. Wright, H.L.; Moots, R.J.; Bucknall, R.C.; Edwards, S.W. Neutrophil function in inflammation and inflammatory diseases. Rheumatology (Oxf.) 2010, 49, 1618-1631. [CrossRef] [PubMed]

9. Krotova, K.; Khodayari, N.; Oshins, R.; Aslanidi, G.; Brantly, M.L. Neutrophil elastase promotes macrophage cell adhesion and cytokine production through the integrin-Src kinases pathway. Sci. Rep. 2020, 10, 15874. [CrossRef] [PubMed]

10. Kawabata, K.; Hagio, T.; Matsuoka, S. The role of neutrophil elastase in acute lung injury. Eur. J. Pharmacol. 2002, 451, 1-10. [CrossRef]

11. Chua, F.; Dunsmore, S.E.; Clingen, P.H.; Mutsaers, S.E.; Shapiro, S.D.; Segal, A.W.; Roes, J.; Laurent, G.J. Mice lacking neutrophil elastase are resistant to bleomycin-induced pulmonary fibrosis. Am. J. Pathol. 2007, 170, 65-74. [CrossRef] [PubMed]

12. Dittrich, A.S.; Kuhbandner, I.; Gehrig, S.; Rickert-Zacharias, V.; Twigg, M.; Wege, S.; Taggart, C.C.; Herth, F.; Schultz, C.; Mall, M.A. Elastase activity on sputum neutrophils correlates with severity of lung disease in cystic fibrosis. Eur. Respir. J. 2018, 51, 1701910. [CrossRef] [PubMed]

13. AbdulWahab, A.; Allangawi, M.; Thomas, M.; Bettahi, I.; Sivaraman, S.K.; Jerobin, J.; Chandra, P.; Ramanjaneya, M.; Abou-Samra, A.B. Sputum and Plasma Neutrophil Elastase in Stable Adult Patients With Cystic Fibrosis in Relation to Chronic Pseudomonas Aeruginosa Colonization. Cureus 2021, 13, e15948.

14. Vaguliene, N.; Zemaitis, M.; Lavinskiene, S.; Miliauskas, S.; Sakalauskas, R. Local and systemic neutrophilic inflammation in patients with lung cancer and chronic obstructive pulmonary disease. BMC Immunol. 2013, 14, 36. [CrossRef] [PubMed]

15. Ocana, A.; Nieto-Jimenez, C.; Pandiella, A.; Templeton, A.J. Neutrophils in cancer: Prognostic role and therapeutic strategies. Mol. Cancer 2017, 16, 137. [CrossRef] [PubMed]

16. Yang, R.; Zhong, L.; Yang, X.Q.; Jiang, K.L.; Li, L.; Song, H.; Liu, B.Z. Neutrophil elastase enhances the proliferation and decreases apoptosis of leukemia cells via activation of PI3K/Akt signaling. Mol. Med. Rep. 2016, 13, 4175-4182. [CrossRef]

17. Wu, M.; Ma, M.; Tan, Z.; Zheng, H.; Liu, X. Neutrophil: A New Player in Metastatic Cancers. Front. Immunol. 2020, 11, 565165. [CrossRef]

18. Uribe-Querol, E.; Rosales, C. Neutrophils in Cancer: Two Sides of the Same Coin. J. Immunol. Res. 2015, 2015, 983698. [CrossRef]

19. Foekens, J.A.; Ries, C.; Look, M.P.; Gippner-Steppert, C.; Klijn, J.G.; Jochum, M. The prognostic value of polymorphonuclear leukocyte elastase in patients with primary breast cancer. Cancer Res. 2003, 63, 337-341.

20. Yamashita, J.; Ogawa, M.; Abe, M.; Hayashi, N.; Kurusu, Y.; Kawahara, K.; Shirakusa, T. Tumor neutrophil elastase is closely associated with the direct extension of non-small cell lung cancer into the aorta. Chest 1997, 111, 885-890. [CrossRef]

21. Nozawa, F.; Hirota, M.; Okabe, A.; Shibata, M.; Iwamura, T.; Haga, Y.; Ogawa, M. Elastase activity enhances the adhesion of neutrophil and cancer cells to vascular endothelial cells. J. Surg. Res. 2000, 94, 153-158. [CrossRef] [PubMed]

22. Nawa, M.; Osada, S.; Morimitsu, K.; Nonaka, K.; Futamura, M.; Kawaguchi, Y.; Yoshida, K. Growth effect of neutrophil elastase on breast cancer: Favorable action of sivelestat and application to anti-HER2 therapy. Anticancer Res. 2012, 32, 13-19. [PubMed] 
23. Wada, Y.; Yoshida, K.; Hihara, J.; Konishi, K.; Tanabe, K.; Ukon, K.; Taomoto, J.; Suzuki, T.; Mizuiri, H. Sivelestat, a specific neutrophil elastase inhibitor, suppresses the growth of gastric carcinoma cells by preventing the release of transforming growth factor-alpha. Cancer Sci. 2006, 97, 1037-1043. [CrossRef] [PubMed]

24. Ho, A.S.; Chen, C.H.; Cheng, C.C.; Wang, C.C.; Lin, H.C.; Luo, T.Y.; Lien, G.S.; Chang, J. Neutrophil elastase as a diagnostic marker and therapeutic target in colorectal cancers. Oncotarget 2014, 5, 473-480. [CrossRef] [PubMed]

25. Xu, Y.; Zhang, J.; Han, J.; Pan, X.; Cao, Y.; Guo, H.; Pan, Y.; An, Y.; Li, X. Curcumin inhibits tumor proliferation induced by neutrophil elastase through the upregulation of alpha1-antitrypsin in lung cancer. Mol. Oncol. 2012, 6, 405-417. [CrossRef] [PubMed]

26. Wang, Z.Q.; Chen, L.Q.; Yuan, Y.; Wang, W.P.; Niu, Z.X.; Yang, Y.S.; Cai, J. Effects of neutrophil elastase inhibitor in patients undergoing esophagectomy: A systematic review and meta-analysis. World J. Gastroenterol. 2015, 21, 3720-3730. [CrossRef]

27. Stockley, R.; De Soyza, A.; Gunawardena, K.; Perrett, J.; Forsman-Semb, K.; Entwistle, N.; Snell, N. Phase II study of a neutrophil elastase inhibitor (AZD9668) in patients with bronchiectasis. Respir. Med. 2013, 107, 524-533. [CrossRef]

28. Chen, K.J.; Chen, Y.L.; Ueng, S.H.; Hwang, T.L.; Kuo, L.M.; Hsieh, P.W. Neutrophil elastase inhibitor (MPH-966) improves intestinal mucosal damage and gut microbiota in a mouse model of 5-fluorouracil-induced intestinal mucositis. Biomed. Pharmacother. 2021, 134, 111152. [CrossRef]

29. von Nussbaum, F.; Li, V.M.; Allerheiligen, S.; Anlauf, S.; Barfacker, L.; Bechem, M.; Delbeck, M.; Fitzgerald, M.F.; Gerisch, M.; Gielen-Haertwig, H.; et al. Freezing the Bioactive Conformation to Boost Potency: The Identification of BAY 85-8501, a Selective and Potent Inhibitor of Human Neutrophil Elastase for Pulmonary Diseases. ChemMedChem 2015, 10, 1163-1173. [CrossRef]

30. Watz, H.; Nagelschmitz, J.; Kirsten, A.; Pedersen, F.; van der Mey, D.; Schwers, S.; Bandel, T.J.; Rabe, K.F. Safety and efficacy of the human neutrophil elastase inhibitor BAY 85-8501 for the treatment of non-cystic fibrosis bronchiectasis: A randomized controlled trial. Pulm Pharmacol. Ther. 2019, 56, 86-93. [CrossRef]

31. Barth, P.; Bruijnzeel, P.; Wach, A.; Sellier Kessler, O.; Hooftman, L.; Zimmermann, J.; Naue, N.; Huber, B.; Heimbeck, I.; Kappeler, D.; et al. Single dose escalation studies with inhaled POL6014, a potent novel selective reversible inhibitor of human neutrophil elastase, in healthy volunteers and subjects with cystic fibrosis. J. Cyst. Fibros 2020, 19, 299-304. [CrossRef]

32. Kistowski, M.; Debski, J.; Karczmarski, J.; Paziewska, A.; Oledzki, J.; Mikula, M.; Ostrowski, J.; Dadlez, M. A Strong Neutrophil Elastase Proteolytic Fingerprint Marks the Carcinoma Tumor Proteome. Mol. Cell Proteomics 2017, 16, 213-227. [CrossRef]

33. Yamashita, J.; Akizuki, M.; Jotsuka, T.; Harao, M.; Nakano, S. Neutrophil elastase predicts trastuzumab responsiveness in metastatic breast cancer. Breast J. 2006, 12, 288. [CrossRef]

34. Jain, M.; Venkatraman, G.; Batra, S.K. Optimization of radioimmunotherapy of solid tumors: Biological impediments and their modulation. Clin. Cancer Res. 2007, 13, 1374-1382. [CrossRef]

35. Holliger, P.; Hudson, P.J. Engineered antibody fragments and the rise of single domains. Nat. Biotechnol. 2005, 23, 1126-1136. [CrossRef]

36. Nam, D.H.; Lee, K.B.; Kruchowy, E.; Pham, H.; Ge, X. Protease Inhibition Mechanism of Camelid-like Synthetic Human Antibodies. Biochemistry 2020, 59, 3802-3812. [CrossRef]

37. Lopez, T.; Mustafa, Z.; Chen, C.; Lee, K.B.; Ramirez, A.; Benitez, C.; Luo, X.; Ji, R.R.; Ge, X. Functional selection of protease inhibitory antibodies. Proc. Natl. Acad. Sci. USA 2019, 116, 16314-16319. [CrossRef] [PubMed]

38. Wu, Y.; Eigenbrot, C.; Liang, W.C.; Stawicki, S.; Shia, S.; Fan, B.; Ganesan, R.; Lipari, M.T.; Kirchhofer, D. Structural insight into distinct mechanisms of protease inhibition by antibodies. Proc. Natl. Acad. Sci. USA 2007, 104, 19784-19789. [CrossRef] [PubMed]

39. Sun, Z.; Chen, C.; Li, W.; Martinez, D.R.; Drelich, A.; Baek, D.S.; Liu, X.; Mellors, J.W.; Tseng, C.T.; Baric, R.S.; et al. Potent neutralization of SARS-CoV-2 by human antibody heavy-chain variable domains isolated from a large library with a new stable scaffold. MAbs 2020, 12, 1778435. [CrossRef] [PubMed]

40. Li, W.; Schafer, A.; Kulkarni, S.S.; Liu, X.; Martinez, D.R.; Chen, C.; Sun, Z.; Leist, S.R.; Drelich, A.; Zhang, L.; et al. High Potency of a Bivalent Human VH Domain in SARS-CoV-2 Animal Models. Cell 2020, 183, 429-441 e16. [CrossRef]

41. Gregory, A.D.; Kliment, C.R.; Metz, H.E.; Kim, K.H.; Kargl, J.; Agostini, B.A.; Crum, L.T.; Oczypok, E.A.; Oury, T.A.; Houghton, A.M. Neutrophil elastase promotes myofibroblast differentiation in lung fibrosis. J. Leukoc. Biol. 2015, 98, 143-152. [CrossRef] [PubMed]

42. Houghton, A.M.; Rzymkiewicz, D.M.; Ji, H.; Gregory, A.D.; Egea, E.E.; Metz, H.E.; Stolz, D.B.; Land, S.R.; Marconcini, L.A.; Kliment, C.R.; et al. Neutrophil elastase-mediated degradation of IRS-1 accelerates lung tumor growth. Nat. Med. 2010, 16, 219-223. [CrossRef]

43. Studer, G.; Rempfer, C.; Waterhouse, A.M.; Gumienny, R.; Haas, J.; Schwede, T. QMEANDisCo-distance constraints applied on model quality estimation. Bioinformatics 2020, 36, 2647. [CrossRef]

44. Waterhouse, A.; Bertoni, M.; Bienert, S.; Studer, G.; Tauriello, G.; Gumienny, R.; Heer, F.T.; de Beer, T.A.P.; Rempfer, C.; Bordoli, L.; et al. SWISS-MODEL: Homology modelling of protein structures and complexes. Nucleic Acids Res. 2018, 46, W296-W303. [CrossRef] 